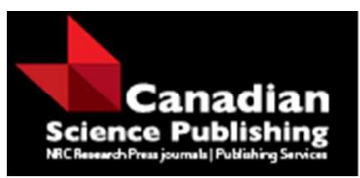

Canadian Journal of Forest Research Revue canadienne de recherche forestière

\title{
Conserving woodland caribou habitat while maintaining timber yield: A graph theory approach
}

\begin{tabular}{|r|l|}
\hline Journal: & Canadian Journal of Forest Research \\
\hline Manuscript ID & cjfr-2015-0431.R2 \\
\hline Manuscript Type: & Article \\
\hline Date Submitted by the Author: & 29-Apr-2016 \\
\hline Complete List of Authors: & $\begin{array}{l}\text { Ruppert, Jonathan; University of Toronto, } \\
\text { Fortin, Marie-Josée; University of Toronto, } \\
\text { Gunn, Eldon; Dalhousie University } \\
\text { Martell, David; University of Toronto, }\end{array}$ \\
\hline Keyword: & $\begin{array}{l}\text { economic values, ecological values, graph theory, least-cost paths, habitat } \\
\text { configuration }\end{array}$ \\
\hline & \\
\hline
\end{tabular}


1 Title: Conserving woodland caribou habitat while maintaining timber yield: A graph theory

2 approach

3 Jonathan L.W. Ruppert ${ }^{1 *}$, Marie-Josée Fortin ${ }^{2}$, Eldon A. Gunn ${ }^{3 \dagger}$ and David L. Martell ${ }^{1}$

$4 \quad{ }^{1}$ Faculty of Forestry, University of Toronto, 33 Willcocks Street, Toronto ON, Canada, M5S 3B3

$5 \quad{ }^{2}$ Department of Ecology and Evolutionary Biology, University of Toronto,

6 mariejosee.fortin@utoronto.ca

$7 \quad{ }^{3}$ Department of Industrial Engineering, Dalhousie University

$8 \quad{ }^{4}$ Faculty of Forestry, University of Toronto, david.martell@utoronto.ca

$9 \dagger$ Deceased

$10 *$ corresponding author:

Jonathan L.W. Ruppert

751 General Services Building

Department of Renewable Resources University of Alberta, Edmonton, AB, T6G 2H1

Fax: 780-492-4323

Telephone: 1-647-205-8636

Email: jruppert@ualberta.ca

Type of Article: Standard Article

Total Manuscript Length (words): 8,006

Abstract: 200

Main Text: 5,942

Acknowledgements: 69

References: 1,311

Table and Figure Legends: 484

Number of Tables: 2

Number of Figures: 8

Number of Supplementary Figures: 5

Number of References: 53

Manuscript Date: April 29, 2016 


\section{Abstract}

31 The fragmentation and loss of old-growth forest has led to the decline of many forest dwelling

32 species that depend on old-growth forest as habitat. Emblematic of this issue in many areas of

33 the managed boreal forest in Canada, is the threatened woodland caribou (Rangifer tarandus

34 caribou). We develop a methodology to help determine when and how timber can be harvested

35 in order to best satisfy both industrial timber supply and woodland caribou habitat requirements.

36 To start, we use least-cost paths based on graph theory, to determine the configuration of

37 woodland caribou preferred habitat patches. We then developed a heuristic procedure to schedule

38 timber harvesting based on a trade-off between merchantable wood volume and the remaining

39 amount of habitat and its connectivity during a planning cycle. Our heuristic can attain $84 \%$ of

40 the potential woodland caribou habitat that would be available in the absence of harvesting, at

41 the end of a 100-year planning horizon. Interestingly, this is more than the current plan (50\%)

42 and a harvesting plan that targets high volume stands (32\%). Our results indicate that our

43 heuristic procedure (i.e., an ecologically-tuned optimization approach) may better direct

44 industrial activities to improve old growth habitat while maintaining specified timber production

45 levels.

46

47 Keywords (3-5): economic values, ecological values, graph theory, least-cost paths, habitat configuration 


\section{Introduction}

53 Globally, industrial forest management practices have directly contributed to the widespread

54 fragmentation and loss of old-growth forests (Lindenmayer et al. 2012). Industrial management

55 practices can also, for example, modify the frequency and severity of several different types of

56 forest disturbances that contribute to the fragmentation and loss of old-growth forest stands,

57 including: timber harvesting, wildfire, insect outbreaks and land use change (Butchart et al.

58 2010; Brandt et al. 2013). As a consequence, declines in biodiversity tend to be related to many

59 of these modified forest landscapes (Butchart et al. 2010; Burivalova et al. 2014; Venier et al. majority of this range recession is occurring alongside areas of land use change and industrial

64 timber production in the boreal forest region, where the area disturbed by harvesting activity in these managed regions can now well exceed the area disturbed due to natural disturbances (Brandt et al. 2013; Venier et al. 2014). As a result, reviews by the Committee on the Status of

67 Endangered Wildlife in Canada (COSEWIC) have led to the listing of woodland caribou as a threatened species throughout many regions (COSEWIC 2000; COSSARO 2005).

72 have altered fire disturbance patterns by producing a greater number of small fires and increasing

73 the mean fire return interval (Martell \& Sun 2008; Venier et al. 2014). This change in fire

74 disturbance, within the managed regions, may provide woodland caribou with more habitat, by 
75 reducing the amount of area impacted by fire, but at the same time the added pressures of timber

76 harvesting, linear features and other changes in land use (e.g., transportation networks, utility

77 corridors) have become the major contributors to increased fragmentation and habitat loss

78 (Environment Canada 2011; Venier et al. 2014). Woodland caribou are affected by

79 fragmentation and habitat loss through decreases in resource availability, primarily terrestrial

80 lichen understorey, through the avoidance of roads (i.e., traffic), and by increases in predator

81 populations (Wittmer et al. 2005; Vors et al. 2007; Thompson et al. 2015). Forest disturbances

82 reduce lichen availability, which can contribute to poor body condition and reduced calf survival

83 rates (Parker et al. 2005; Thompson et al. 2015). Additionally, forest disturbances contribute to

84 increases in the amount of early seral boreal forest. This increases suitable forage for white-tailed

85 deer (Odocoileus virginianus) and moose (Alces alces andersoni) populations (Wittmer et al.

86 2005). Subsequent increases in the abundance of deer and moose populations, desirable prey

87 species for black bears (Ursus americanus) and wolves (Canis lupus), have led to increases in

88 predator populations that will opportunistically prey upon woodland caribou thereby increasing

89 their predation pressure (Wittmer et al. 2005). Thus, harvesting activities that fragment and

90 reduce the amount of preferred habitat, are believed to be a major contributor to woodland

91 caribou declines by altering resource availability and increasing predation pressure.

92 To achieve long-term sustainability of forested landscapes, managers are required to develop

93 sustainable forest management plans that achieve an appropriate balance of multiple economic,

94 ecological, and social objectives (Gunn 2007; Adams 2014). Management of industrial wood

95 supply in Ontario provides a good study system, as there is conflict between the southern range

96 limit of woodland caribou and northern limit of timber production for industry within the

97 province (Figure 1). Further, there is already a harvesting strategy that is designed to mitigate the 
98

99

100

101

102

103

104

105

106

107

108

109

110

111

112

113

114

115

116

117

118

119

120

impacts of timber harvesting on woodland caribou habitat, termed the Dynamic Caribou Habitat Schedule (DCHS; hereafter referred to as the caribou mosaic), which has been in place for the last 10-15 years depending on the specific location (Racey et al. 1999; OMNR 2014). One limitation to this strategy is its deterministic design wherein the spatial arrangement of cut blocks, which includes the area, position and perimeter of areas available for harvesting, are specified for an entire 100+ year planning horizon at the start of that planning horizon. Using a deterministic design such as this may be problematic when considering how dynamic a forested ecosystem can be over century long time periods due to the possible but uncertain potential changes to the forest landscape (e.g., forest stand composition, habitat conditions), marketplace

(e.g., value of timber, forest products), or social values (e.g. management objectives; Rayfield et al. 2008; Savage et al. 2010). This is one reason why, long-term harvest schedules generated by planning models are not implemented beyond the first planning cycle (e.g., 10 years for the caribou mosaic). Periodically (e.g., every 5 or 10 years) a new plan is usually developed to allow managers to adapt their plans to changing conditions (called replanning) when the current plan becomes infeasible or suboptimal for industry and/or woodland caribou needs (Gunn 1991; Martell et al. 1998; Baskent \& Keles 2005). Current harvest strategies are developed with replanning in mind and since replanning is not directly incorporated into its framework, it may not reflect well, what changes might actually take place on the forest landscape, in the marketplace, or on ecological values over the long-term.

A second limitation is that there is currently a management focus on maintaining or increasing preferred habitat area by reducing the cumulative area of disturbance to woodland caribou across the landscape (OMNR 2009a ; Environment Canada 2011). However, as is the case with many other species, woodland caribou move through the landscape on an annual basis 
121 and will demonstrate some site fidelity from year-to-year (i.e., they will tend to use the same

122 areas from year-to-year; Ferguson \& Elkie 2004). On the other hand, there are some seasons

123 during which such site fidelity does not appear to hold very well (e.g., winter grounds can

124 change location by 6-15 km year-to-year; Ferguson \& Elkie 2004). This implies that considering

125 the configuration of preferred habitat, a combination of connectivity and area, may be a good

126 approach when the use of particular habitat patches can be quite variable year-to-year in the

127 effort for woodland caribou to gain access to resources and to avoid predation (O'Brien et al.

128 2006; Mayor et al. 2007; Hins et al. 2009). In other words, providing habitat is necessary to

129 achieve conservation goals, but if habitat is highly fragmented, it may not be sufficient due to the

130 movement patterns and constraints of the species of concern (Fahrig 1998; Fahrig 2003; Baskent

131 \& Keles 2005; Hanski 2005). This potential shortcoming indicates that explicitly incorporating

132 the configuration of preferred habitat into management plans may be crucial, especially if

133 industrial timber production activities can potentially worsen preferred habitat configuration for

134 woodland caribou.

135 In our study, we address these simplifying assumptions (no replanning and no explicit

136 consideration of the spatial arrangement of habitat) by developing a harvesting strategy that is

137 assessed in terms of the economic values for industry and habitat values for woodland caribou

138 within each forest stand during each planning period. We begin by determining the value of a

139 forest stand based on woodland caribou habitat preferences and the spatial configuration of

140 preferred habitat patches (area and connectivity) within the landscape to facilitate woodland

141 caribou movement in the managed forested landscape. We then formulate and use a harvest

142 scheduling heuristic that selects forest stands for harvest based on the volume of merchantable

143 timber in the stand and the woodland caribou habitat value of a forest stand during each period of 
144 the planning horizon. Finally, we evaluate four harvesting strategies (including the current 145 caribou mosaic plan and our harvesting heuristic) to investigate long-term trade-offs of wood 146 supply and woodland caribou conservation.

148 Methods

149 Study Area and Data

150 Our study area is the Trout Lake forest located in northwestern Ontario (Figure 1). The Trout 151 Lake forest is an area of approximately one million hectares within the boreal forest region of 152 Canada. It is an area of active timber production and provides habitat for woodland caribou 153 (Figure 1; OMNR 2009a; Environment Canada 2011). We used Forest Resource Inventory (FRI) 154 data updated to 2012 (provided by the Ontario Ministry of Natural Resources and Forests) to 155 classify woodland caribou habitat and evaluate forest harvesting strategies (OMNR 2009b). We 156 first created forest planning units that are $62,500 \mathrm{~m}^{2}$ (or $6.25 \mathrm{ha}$ ) in size and classified them as 157 being either a type of forest (designated as one of twelve forest types to be managed using to one 158 of four silviculture strategies) or a non-forest unit (e.g., water, wetland, treed muskeg; see 159 OMNR 2009b for more details). As of 2012, we found that the age class distribution of forest 160 stands in the Trout Lake forest is multimodal with peaks at 0-20, 40-60 and 90-110 years (Figure S1A), which is a result of recent timber harvesting activities ( $<20$ years) and the legacy of large natural disturbances such as fire (OMNR 2009a). The Trout Lake forest is dominated by 163 coniferous canopy species, black spruce (Picea mariana) and jack pine (Pinus banksiana), which 164 make up $>80 \%$ of the forest canopy (Figure S1B).

Forest management plans in northwestern Ontario are developed using a hierarchical

166 design process where, at the highest level, wood production is constrained by what is termed the 
167 Dynamic Caribou Habitat Schedule (DCHS). Briefly, the DCHS constrains wood production 168 temporally across tracts of land over a 100-year block rotation (Racey et al. 1999; OMNR 2014).

169 The Trout Lake forest was partitioned into seven zones that are subject to the following temporal 170 harvest constraints: reserve zones (no harvesting), harvesting anytime (0-100 years), and 171 harvesting to occur in block A (0-20 years), block B (21-40 years), block C (41-60 years), block 172 D (61-80 years), and block E (81-100 years; Figure S2). Finally, since the first 13 years of this 173 plan for the Trout Lake forest was implemented beginning in year 2012, we start our analysis 174 with the last 7 years in the A blocks (Figure S2A), before moving in sequential order through 175 blocks B, C, D, and E. For simplicity, we refer to this remaining 7 years as the first 10 years of 176 all harvesting strategies within this study. Long-term harvesting and silviculture plans are derived from the current management 178 plan, where harvest scheduling has been determined using the Strategic Forest Management 179 Model (SFMM; OMNR 2009a). SFMM (a variant of Model III) is not a spatially explicit 180 planning model that can incorporate both deterministic and stochastic processes through the use 181 of deterministic mean rates of succession and natural disturbance processes (Boychuk \& Martell 182 1996; OMNR 2007). In this instance, the spatial aspect of harvest planning is implemented in 183 SFMM by using regional constraints (or zones) that specify when harvesting can take place in 184 each zone (Figure S2). We use annual target volumes outlined in the current plan for the Trout 185 Lake forest, ranging between $670,000-865,000 \mathrm{~m}^{3}$ per annum, when harvest occurs in any of 186 our strategies (OMNR 2009a).

187 Economic timber and caribou habitat value of a forest stand

188 We consider two different values of a forest; the economic value of the timber and the woodland 189 caribou conservation value, both of which are incorporated into our heuristic (see Figure 2 for 
190 details). The economic value of the timber is based on the volume of merchantable wood in a

191 forest stand. To estimate the volume of a given forest stand we used yield curves currently

192 defined and used in strategic forest management strategies for the Trout Lake forest management

193 unit (Penner et al. 2008; OMNR 2009a).

The woodland caribou conservation value of a forest stand was determined by first

195 classifying the FRI data (or forest planning units) based primarily on winter habitat preferences,

196 which generally reflect the habitat requirements of woodland caribou throughout the year

197 (O'Brien et al. 2006; Environment Canada 2011; McGreer et al. 2015). Winter habitat use occurs

198 during a critical period for woodland caribou, where they face decreased availability of resources

199 and harsh weather, which can have a dramatic impact on survival (Parker et al. 2005). Here we

200 define the most preferred habitat type for woodland caribou as mature jack pine stands (jack pine

201 stands with an age of greater than 60 years), rocky outcrops, and shallow soil sites, which likely

202 sustain high levels of terrestrial lichen understory (a preferred resource for woodland caribou;

203 Table 1 and Figure 3A). In contrast, recently (<20 years) disturbed areas (cutovers or burns) and

204 linear features (roads and utility corridors) are the least desired landscape features for woodland

205 caribou (Table 1 and Figure 3A). We also used $500 \mathrm{~m}$ buffers of influence for edge effects of

206 disturbances that negatively impact woodland caribou (i.e., recently disturbed areas (age $<20$

207 years) and linear features, such as roads and utility corridors; Environment Canada 2011). Linear

208 features, such as roads and utility corridors, were obtained from Ontario Base Maps and included

209 both current road infrastructure and utility corridors throughout the Trout Lake forest (OMNR

210 2003). As we are primarily interested in assessing the impact of harvest schedule plans (i.e., the

211 placement and area of harvest), we only included the current configuration of roads and utility

212 corridors. For the purpose of this research, we did not model for future road creation and 
213 decommissioning that may take place in the Trout Lake forest. Calving habitats, which are

214 critical to successful woodland caribou reproduction (e.g., small islands, peninsulas and muskeg)

215 were accounted for by being present in reserves as well as by being classified as highly suitable

216 habitats (Table 1). Here we refer to a caribou habitat patch as the most preferred habitat type

217 (Table 1), where the smallest sized patch is a single forest stand (6.25 ha). Habitat classifications

218 were conducted using both Python v2.7.8 and ArcGIS 10.2 software.

After ranking habitat preferences of each stand we created a cost surface for woodland caribou that reflects their habitat use and movement within the Canadian Shield region of the 221 boreal forest in northwestern Ontario (Table 1). Using this cost surface we then use a graph 222 theoretical approach with preferred habitat as nodes (where adjoining preferred habitat stands are 223 merged) and least-cost paths as arcs delineating potential direct movement between patches 224 (Adriaensen et al. 2003; Fall et al. 2007). Least-cost paths represent potential movement paths 225 for which no other path between two habitat patches has a lower cost (i.e., lowest cost given the 226 distance travelled and avoidance of highly unsuitable or "costly" habitat; see Adriaensen et al. 2272003 and Fall et al. 2007 for more details). This routine was implemented using the R software 228 grainscape package that invokes the Spatially Explicit Landscape Event Simulator (SELES) 229 algorithm to implement least-cost path routines (Fall et al. 2007; Galpern et al. 2012).

231 landscape, we first determine the overall landscape value and calculate the marginal contribution 232 of a habitat patch to the overall landscape using the Equivalent Connected Area (ECA) metric 233 (Eq. 1):

$$
E C A=\sqrt{\sum_{i=1}^{n} \sum_{j=1}^{n} a_{i} a_{j} p_{i j}}
$$


235 where, $a_{i}$ is the area of habitat patch $i, a_{j}$ is the area of patch $j, p_{i j}$ is the maximum product

236 probability of movement between patch $i$ and $j$, and $n$ is the total number of patches on the

237 landscape (Saura et al. 2011). The probability of direct dispersal (i.e., the probability that a

238 woodland caribou will move to a patch without using other patches) between all patches is

239 calculated using a negative exponential dispersal kernel, which is defined by an alpha parameter

$240(\alpha=0.5)$ and the length of a least-cost link $(d)$ between patches $(\log (\alpha) / d$; Urban \& Keitt 2001;

241 Saura et al. 2011). The maximum product probability $\left(p_{i j}\right)$ is then calculated as the maximum

242 probability of movement using all potential paths between patches $i$ and $j$, including paths that

243 utilize other patches (Figure S3; see supplementary for details). Throughout this study we only

244 present one solution for simplicity and use a median dispersal distance of $40 \mathrm{~km}$, which provides

245 the largest improvement in overall habitat area on the Trout Lake forest landscape (Figure S4)

246 and represents a balance between a range of movements representing approximate daily (1 km)

247 and annual $(80 \mathrm{~km})$ movement distances for woodland caribou within the region (Ferguson \&

248 Elkie 2004). Then to assess each harvesting strategy, we perform a sensitivity analysis of the

249 ECA landscape metric using five different median dispersal distances (1, 10, 25, 40, $80 \mathrm{~km})$.

250 Lastly, to calculate the marginal value of each patch we perform a take-one-out procedure to

251 calculate the contribution of each patch to the overall landscape ECA value. This procedure is

252 conducted in $\mathrm{R}$ software using packages igraph and raster within this routine (R Development

253 Core Team 2015).

254 Harvesting heuristic

255 We designed a harvesting heuristic to maximize ECA during each planning period by selecting

256 for harvest, stands that have large wood volumes, but that are located away from high value

257 woodland caribou habitat patches (Eq. 2). Specifically, the heuristic harvest value is weighted 
258 function of the volume of merchantable wood in the stand were it to be harvested and the

259 decrease in suitable habitat that might result. Forest stands are scheduled to be harvested in each

260 planning period such that the highest heuristic harvest value stands $\left(H_{i}\right)$ are targeted first until

261 wood volume constraints are met (Figure 2), where the harvest value is:

$$
H_{i}=b\left(V_{i}\right)-c\left(\frac{E C A_{i}}{\left(1+D_{i}\right)}\right)
$$

263 Here, the heuristic harvest value $\left(H_{i}\right)$ of a stand includes the parameters $b$ and $c, V_{i}$ is the total

264 volume of merchantable wood in the stand $\left(\mathrm{m}^{3}\right), E C A_{i}$ is the marginal equivalent connected area

265 value of the nearest habitat patch (hectares), and $D_{i}$ is the distance to the nearest woodland

266 caribou habitat patch (metres). The parameters allow the heuristic to be tuned to achieve a range

267 of objectives. Setting $b>c$ would put more emphasis on harvesting high volume stands, whereas

268 setting $b<c$ would emphasize harvesting stands further away from caribou habitat (see Figure

269 S5). For the purposes of this study we set values for parameters at $b=c=1$, which produced the

270 harvest values for each forest stand on the initial landscape in the Trout Lake forest shown in

271 Figure 3B.

272

Harvest scheduling comparisons

273 We then used deterministic succession rules (stands age, but do not change types through time)

274 with no fire on our landscape, to assess the utility and impact of using this heuristic. Although

275 succession is admittedly not a purely deterministic process, current strategic forest management

276 models (SFMM) use successional processes in a deterministic fashion (OMNR 2009a). Further,

277 we are interested in assessing how harvesting strategies may work in relation to habitat

278 configuration and have opted to not evaluate these alongside the added complexity of stochastic

279 processes (e.g., fire, succession, insect outbreaks) at this stage. We evaluated four harvest 
280 strategies for comparison; (1) no harvesting, (2) relaxed caribou mosaic (no regional spatial 281 constraints, except no harvesting in designated reserves), (3) caribou mosaic (the current cut 282 block rotation applied to the Trout Lake forest; DCHS), and (4) our harvesting heuristic. For the 283 caribou mosaic strategy, regional spatial constraints are present (Figure S2), whereas the relaxed 284 caribou mosaic strategy does not have any regional spatial constraints, except for precluding 285 harvesting within reserves. With the relaxed caribou mosaic and caribou mosaic strategies, when 286 harvest constraints are met, forest stands with higher volumes of wood are always selected in 287 decreasing order from highest to lowest. For the harvesting heuristic, harvesting occurs in order 288 of harvest value (Eq. 2), where higher values are targeted first (reserves are not included in the 289 harvest allocation; Figure 2). Harvest allocation continues with all strategies until timber 290 production volume targets have been satisfied for each planning period. All harvesting strategies 291 and routines were developed using Python v2.7.8 and ArcGIS 10.2 software.

To assess differences between harvesting strategies we needed to evaluate how the 293 landscape is predicted to change over the course of the planning horizon with respect to 294 woodland caribou habitat. Since the ECA metric is our objective function in the harvesting 295 heuristic strategy we first assess how the ECA of each harvesting strategy changes through time 296 using five different median dispersal distances $(1,10,25,40$, and $80 \mathrm{~km})$. However, because 297 using the ECA may be viewed as being circular (i.e., using the ECA to evaluate its own 298 performance or metrics similar to ECA (e.g., overall area)), we partitioned the landscape into one 299 portion that was harvested (at least once) and another portion that is never harvested over the 300 course of the 100-year planning horizon. We then assessed how the number of patches and the 301 amount of preferred woodland caribou habitat differed within harvested and non-harvested areas 302 on the landscape for each strategy. 


\section{Results}

304 Comparing the overall habitat configuration

305 The four strategies we evaluated produced quite different woodland caribou habitat area and 306 connectivity trajectories over the planning horizon (Figure 4). As expected, under a strategy with 307 no harvesting, the (i.e., the average across different dispersal distances of $1,10,25,40$, and 80 $308 \mathrm{~km}$ ) landscape area and connectivity of woodland caribou habitat would improve the most over 309 time (Figure 4A and 4B). With timber harvesting, our harvesting heuristic provides the highest 310 improvement and maintenance of habitat area and connectivity for woodland caribou over the 311 course of the planning horizon (Figure 4A and 4C). Interestingly, the current caribou mosaic 312 strategy in Ontario provides an initial improvement over the first 30 years of the planning 313 horizon (Figure 4A and 4D), but after that point in time it exhibits a declining value of woodland 314 caribou habitat area and connectivity. Finally, not surprisingly the relaxed caribou mosaic 315 strategy consistently performs the worst with respect to improving and maintaining woodland 316 caribou habitat area and connectivity across the landscape (with the exception of the 80 year time 317 period; Figure 4A and 4E). In fact, over the long-term (>60 years), the relaxed caribou mosaic 318 strategy has a woodland caribou habitat area and connectivity across the landscape that is similar 319 to the current caribou mosaic strategy (Figure 4A), where both strategies are almost consistently 320 well below the no harvesting strategy. Finally, reductions in harvest levels (by comparing the no 321 harvesting to other harvest strategies) would not lead to large changes in ECA for the harvesting 322 heuristic compared to other strategies (Figure 4A).

323 The four strategies evaluated produce different woodland caribou habitat area and 324 connectivity trajectories over the planning horizon (Figure 5). As expected, under the no 325 harvesting strategy, preferred habitat area and number of patches would improve the most over 
326 time in areas that are not harvested (Figure 5A and 5C). Within areas that are harvested at least

327 once, we find that the caribou mosaic strategy allocates the most preferred habitat in area and

328 number of patches (Figure 5B and 5D) compared to any other strategy. With timber harvesting,

329 we find that our harvesting heuristic provides the highest improvement and maintenance of

330 habitat area and number of patches for woodland caribou within non-harvested areas over the

331 planning horizon (Figure 5A and 5C).

Spatial configuration of woodland caribou habitat and timber harvest

The spatial configuration of woodland caribou habitat is different when comparing the 100-year

334 old simulated landscapes under the four harvesting strategies (Figure 6). The no harvesting

335 strategy provides the largest number of patches, links and habitat area across the Trout Lake

336 forest (Figure 6A and Table 2). When we consider timber harvesting, the harvesting heuristic

337 supplies more habitat than the other harvest strategies considered, but the number of habitat

338 patches and links represents only the third highest of all of the strategies (Figure 6B and Table

339 2). It achieves this by creating larger habitat patches and creates large tracts of habitat patches in

340 the southeast and to a lesser extent, the northwest region of the Trout Lake forest. In contrast, the

341 caribou mosaic strategy produces a larger number of habitat patches and links, although less

342 overall habitat area in comparison to the harvesting heuristic, meaning the habitat patch size is

343 much smaller than that found with the harvesting heuristic (Figure 6C and Table 2). While the

344 caribou mosaic strategy produces some areas that contain a large amount of habitat and

345 connectivity, these are less substantial in size in comparison to the harvesting heuristic. Finally,

346 we find the relaxed caribou mosaic strategy produces the least number of patches, the least

347 number of links and the least amount of habitat compared to other strategies (Figure 6D and 
348 Table 2). The relaxed caribou mosaic strategy produces habitat areas that appear to be smaller in 349 size and widely dispersed.

The resulting configuration of habitat patches and links mirrors that of stands that are selected for harvest over the course of the planning horizon (Figures 6 and 7). The harvesting

352 heuristic concentrates harvesting activities spatially, creating areas in the southeast and to a

353 lesser extent in the northwest, where harvesting does not occur (Figure 7A). The caribou mosaic 354 and relaxed caribou mosaic strategies appear similar in their selection of forest stands over the 355 course of the planning horizon (Figure 7B, 7C). However, where the selection of stands for 356 harvest occurred twice over the planning horizon, the caribou mosaic concentrates these second 357 harvests within the anytime block (Figure S2F, 7B) and the relaxed caribou mosaic strategy 358 distributes these second harvests throughout the Trout Lake forest (Figure 7C).

360 When considering current anthropogenic linear features (e.g., roads and utility corridors) and recent $(<20$ years) forest disturbances with potential edge effects of $500 \mathrm{~m}$, the overall amount 362 of habitat disturbed under the four strategies does not differ dramatically over the course of the 363 100-year planning horizon (Figure 8). We find that the legacy of harvesting and fire within the 364 Trout Lake forest represents a substantial amount of disturbance for woodland caribou over the 365 first 20 years of the planning horizon (Figure 8). As we had expected, the least amount of 366 disturbance across the landscape occurs under the no harvesting strategy (Figure 8). In contrast, 367 the other three harvesting strategies vary within a range of 23-39\% disturbance to woodland 368 caribou within the Trout Lake forest after the first 20 years of the planning horizon (Figure 8). 369 Specifically, after the first 20 years the lowest disturbance values are found with the caribou 370 mosaic strategy (23-35\%), followed by the relaxed caribou mosaic (33-38\%) and the harvesting 
371 heuristic (33-39\%; Figure 8). These values are either within a range that is considered suitable

372 levels of disturbance $(<35 \%)$ or are within a lower range values of disturbance levels that are

373 considered to be uncertain if woodland caribou may be able to tolerate (35-45\%; Environment

374 Canada 2011).

375 Discussion

376 Sustainable forest management plans call for an appropriate balance of multiple objectives.

377 When balancing woodland caribou conservation and industrial economic values, we find that the

378 harvesting heuristic performed better than the other three timber harvesting strategies we

379 considered (Figures 4 and 5). The harvesting heuristic produces more area and a better spatial

380 configuration of habitat for woodland caribou across the landscape compared with the other

381 strategies that schedule timber harvesting to meet industrial needs. Specifically, the harvesting

382 heuristic strategy maintained $84 \%$ of the potential woodland caribou habitat (compared with

$38350 \%$ and $32 \%$ for the caribou mosaic and relaxed caribou mosaic strategies, respectively; Figure

384 4A) on the landscape compared to the amount that could result under conditions with no

385 harvesting at the end of the 100-year planning horizon (Table 2). Interestingly, we found that

386 while the caribou mosaic and relaxed caribou mosaic harvesting strategies produce similar

387 levels of preferred habitat within non-harvested areas, the caribou mosaic provides slightly more

388 preferred habitat by allocating it within areas that will be harvested or have been harvested

389 (Figure 5A). The harvesting heuristic is able to achieve an improvement in levels of habitat

390 configuration and area by allocating most of the harvest away from high value woodland caribou

391 patches (Equation 2 and Figure 7A). In doing so, this harvesting heuristic concentrates

392 anthropogenic activities, which has been demonstrated to be a strategy that may better achieve

393 conservation goals for improving and maintaining levels of old growth boreal forest (a desirable 
394 habitat type for woodland caribou; Tittler et al. 2012; Bouchard \& Garet 2014). Further,

395 concentrating timber harvesting may have an added economic benefit by reducing the amount of

396 roads that need to be built and maintained to access stands for timber production. For these

397 reasons, it appears that the harvesting heuristic strategy may be able to strike a better balance

398 between our two objectives, economic and conservation values, over the course of the planning

399 horizon by producing larger habitat patches with more connectivity, while satisfying current

400 annual wood supply levels.

\section{Incorporating habitat configuration into forest management planning}

402 Habitat guidelines specify that woodland caribou require approximately $65 \%$ of the landscape to 403 not be disturbed by natural and anthropogenic activities (e.g., roads, timber harvesting, fire) with 404 an uncertain result within a range of 55-65\% (Environment Canada 2011). We have

405 demonstrated that under scenarios that do not account for natural disturbances (e.g., fire, insect 406 outbreaks) and focus only on recent known disturbances ( $<20$ years), that this threshold may be 407 met, albeit after an initial 20 year period when the lag effects of recent large scale fires have 408 receded (Figure 8). However, given the relatively short fire return interval for northwestern 409 Ontario ( $~ 84$ years; Boulanger et al. 2012), we may expect that fire on the landscape and the 410 inclusion of future road building may make this $65 \%$ threshold and potentially the $55 \%$ threshold 411 unattainable not only for the Trout Lake forest, but other FMUs within the region.

412 Regardless of whether a percentage disturbance target is attainable alongside projected levels

413 of harvesting activities, it is important to highlight that the overall measure of percent

414 disturbance across the landscape is an aspatial metric. All three timber harvesting strategies 415 evaluated in this study have different spatial habitat configurations, but more similar rates of 416 percent disturbance throughout the planning horizon (Figures 6 and 8). Spatial habitat 
417 configuration has an impact on the ability of species to acquire resources and avoid predation

418 and it can also impact landscape scale processes that includes metapopulation dynamics

419 (exchange of individuals between populations in terms of immigration and emigration; Hanski

420 2005). For woodland caribou in particular, previous studies indicate that habitat configuration is

421 important (O'Brien et al. 2006; Mayor et al. 2007; Hins et al. 2009) as is the impact of edge

422 effects of disturbed and developed (e.g., roads) areas (Vors et al. 2007). Further, habitat

423 configuration will also likely play a more important role when habitat becomes more limited

424 across the landscape (Fahrig 1998), which appears to be the case for many woodland caribou

425 populations within the managed portion of the boreal forest region in Canada (Environment

426 Canada 2011), and that may be the case for many other forest dwelling species (Butchart et al.

427 2010; Burivalova et al. 2014). Thus, at the very least, integrating habitat configuration into forest

428 management planning, as is done a priori with the caribou mosaic strategy (with large spatial

429 zoning) or by allowing more flexibility as shown with the harvesting heuristic strategy, may

430 provide some ways of allowing for higher levels of timber harvesting while also improving and

431 maintaining woodland caribou habitat across the landscape.

432 Limitations and future directions

433 There are several limitations of our methodology, which if addressed, could improve our ability

434 to achieve a better balance between timber production and woodland caribou conservation

435 objectives. Firstly, FMUs in Ontario, while millions of hectares in size and subject to same

436 guidelines, stakeholder input, and decision processes, are developed largely independently of

437 each other (OMNR 2014). This can be problematic given that the size of the ranges of local

438 populations of woodland caribou in northern Ontario, which can encompass 3-5 different FMUs.

439 This means one herd would require habitat that is appropriately distributed across several FMUs, 
440 which is not currently accounted for when forest management plans are developed and

441 implemented at the single FMU level. This begs the question whether forest management plans

442 are at the appropriate spatial scale for woodland caribou conservation and it appears that the

443 management of woodland caribou may require a broader spatial scale of management. Secondly,

444 a critical knowledge gap remains as we understand that habitat configuration is important for

445 woodland caribou (O'Brien et al. 2006; Mayor et al. 2007; Hins et al. 2009), but we do not have a

446 clear understanding of what level of habitat configuration (i.e., equivalent connected area) is

447 required for woodland caribou persistence. A better understanding of habitat configuration and

448 its impact on local population level dynamics (e.g., recruitment) for woodland caribou will

449 undoubtedly better inform both models and forest management practices.

There is also a need to develop a spatial landscape optimization model that can be used to

451 evaluate and potentially improve upon our heuristic (Ohman 2000; Williams et al. 2004; Gunn

452 2007; Carvajal et al. 2015). From an economic perspective, an optimization approach will likely

453 improve stand selection for harvest by incorporating costs alongside revenues, which may result

454 in an altered harvest allocation that could potentially impact woodland caribou habitat differently

455 across the landscape. Secondly, incorporating stochastic processes, such as uncertain fire and

456 forest succession in the boreal forest, should be investigated to determine how uncertainty may

457 impact our ability to achieve the similar outcomes (Boychuk \& Martell 1996; Savage et al.

458 2010). As was suggested in the previous section, including stochastic processes in our

459 methodology would increase disturbance for woodland caribou and would also impact the

460 resulting habitat configuration. This may also highlight other details with the harvesting heuristic

461 strategy, where the selection of stands for harvest can better respond to changing landscape

462 values that may result from uncertain disturbances (e.g., large scale fires). Finally, there is 
463 currently little information on how road networks are constructed (Pulkki 2003), let alone

464 decommissioned, to accurately account for future road building. Regardless, an algorithm based

465 on some simple rules (e.g., roads are not built over water if it can be avoided) could be

466 developed to provide some insight into how future road building alongside timber harvesting

467 may impact woodland caribou.

468 Conclusions

469 Our harvesting heuristic, which is designed to trade-off economic and ecological objectives,

470 produces solutions that will help assess woodland caribou habitat provisioning in the face of

471 fixed timber supply. We demonstrate that by avoiding high woodland caribou value stands one

472 can help offset the detrimental impacts of timber harvesting activities and meet industrial timber

473 supply needs. Further, our harvesting heuristic constitutes a flexible approach to forecasting

474 long-term timber production as it is implemented between planning periods, as opposed to a

475 deterministic design that follows a set strategy over the entire planning horizon. This has a two-

476 fold benefit, economically and ecologically, of responding to changes in values over time, which

477 may lead to more realistic outcomes when assessing long-term impacts of planning decisions.

478 We incorporate spatial considerations in our planning method for woodland caribou

479 conservation, providing harvest scheduling outcomes that have higher levels of habitat area and

480 connectivity between patches. Our results also suggest that if we consider stochastic processes

481 alongside harvesting activities, harvesting rates may need to be reduced if current defined

482 thresholds (e.g., percent disturbance) are used as management guidelines. However, these

483 aspatial guidelines are limited in application and further understanding is required to reduce

484 uncertainty surrounding the spatial constraints of woodland caribou populations. Lastly, the

485 harvesting heuristic strategy framework is also flexible in that it can be easily adapted to 
486 incorporate other forest values, such as Marten (Martes americana) habitat or habitat preferences

487 of other species of interest. In summary, our model suggests that incorporating our current

488 knowledge of species habitat requirements, both habitat preference and its spatial configuration,

489 into timber harvest models will lead to more desirable outcomes for conservation while meeting

490 the economic needs of industry within the boreal forest ecosystem.

491 Acknowledgements

492 The authors would like to thank Bronwyn Rayfield and Colin Daniel for sharing their knowledge 493 about methods and the study system. Thanks are also due to Tom Schiks, Dan Rouillard, Dirk 494 Kloss, and Wenbin Cui for their comments on earlier versions of this manuscript. Funding was 495 provided by the Natural Sciences and Engineering Research Council of Canada Strategic 496 Research Network on Value Chain Optimization (VCO) to E.G. and D.L.M..

497 References

498 Adams, W.M. (2014) The value of valuing nature. Science 346: 549-551.

499 Adriaensen, F., Chardon, J.P., De Blust, G., Swinnen, E., Villalba, S., Gulinck, H. \& Matthysen, 500 E. (2003) The application of 'least-cost' modelling as a functional landscape model.

$501 \quad$ Landscape and Urban Planning 64: 233-247.

502 Baskent, E.Z. \& Keles, S. (2005) Spatial forest planning: A review. Ecological Modelling 188:

$503 \quad 145-173$.

504 Bergerud, A.T. (1974) Decline of Caribou in North-America Following Settlement. Journal of $505 \quad$ Wildlife Management 38: 757-770.

506 Bouchard, M. \& Garet, J. (2014) A framework to optimize the restoration and retention of large mature forest tracts in managed boreal landscapes. Ecological Applications 24: 1689- 
1704.

509

510

511

512

513

514

515

516

517

518

519

520

521

522

523

524

525

526

527

528

529

530

Boulanger, Y., Gauthier, S., Burton, P.J. \& Vaillancourt, M.A. (2012) An alternative fire regime zonation for Canada. International Journal of Wildland Fire 21: 1052-1064.

Boychuk, D. \& Martell, D.L. (1996) A multistage stochastic programming model for sustainable forest-level timber supply under risk of fire. Forest Science 42: 10-26.

Brandt, J.P., Flannigan, M.D., Maynard, D.G., Thompson, I.D. \& Volney, W.J.A. (2013) An introduction to Canada's boreal zone: ecosystem processes, health, sustainability, and environmental issues. Environmental Reviews 21: 207-226.

Burivalova, Z., Sekercioglu, C.H. \& Koh, L.P. (2014) Thresholds of Logging Intensity to Maintain Tropical Forest Biodiversity. Current Biology 24: 1893-1898.

Butchart, S.H.M., Walpole, M., Collen, B., van Strien, A., Scharlemann, J.P.W., Almond, R.E.A., et al. (2010) Global Biodiversity: Indicators of Recent Declines. Science 328: 1164-1168.

Carvajal, R., Constantino, M., Goycoelea, M., Vielma, J.P. \& Weintraub, A. (2015). Imposing connectivity constraints in forest planning models. Operations Research 4: 824-836.

COSEWIC (2000) Canadian species at risk, May 2000. Committee on the Status of Endangered Wildlife in Canada, Environment Canada, Ottawa, Ontario, Canada.

COSSARO (2005). Committee on the Status of Species at Risk in Ontario. Species at risk in Ontario list. Ontario Ministry of Natural Resources, Toronto, Ontario.

Environment Canada (2011) Scientific Assessment to Inform the Identification of Critical Habitat for Woodland Caribou (Rangifer tarandus caribou), Boreal Population, in Canada: 2011 Update. Ottawa, Ontario, Canada. 102 pp. plus appendices.

Fahrig, L. (1998) When does fragmentation of breeding habitat affect population survival? 
Ecological Modelling 105: 273-292.

532 Fahrig, L. (2003) Effects of habitat fragmentation on biodiversity. Annual Review of Ecology Evolution and Systematics 34: 487-515.

534

535

536

537

538

539

540

541

542

543

544

545

546

547

548

549

550

551

552

553

Fall, A., Fortin, M.-J., Manseau, M. \& O'Brien, D. (2007) Spatial graphs: Principles and applications for habitat connectivity. Ecosystems 10: 448-461.

Ferguson, S.H. \& Elkie, P.C. (2004) Seasonal movement patterns of woodland caribou (Rangifer tarandus caribou). Journal of Zoology 262: 125-134.

Galpern, P., Manseau, M. \& Wilson, P. (2012) Grains of connectivity: analysis at multiple spatial scales in landscape genetics. Molecular Ecology 21: 3996-4009.

Gunn, E.A. (1991) Some aspects of heirarchical production planning in forest management. Proceedings of the 1991 Symposium on Systems Analysis in Forest Resources, 74, 54-62.

Gunn, E.A. (2007) Models for Strategic Forest Management. Handbook of Operations Research in Natural Resources (eds A. Weintraub, C. Romero, T. Bjordal \& R. Epstein), pp. 317342. Springer, New York.

Hanski, I. (2005) The shrinking world: ecological consequences of habitat loss. International Ecology Institute. Oldendorf/Luhe, Germany. 307pp.

Hins, C., Ouellet, J.-P., Dussault, C. \& St-Laurent, M.-H. (2009) Habitat selection by forestdwelling caribou in managed boreal forest of eastern Canada: Evidence of a landscape configuration effect. Forest Ecology and Management 257: 636-643.

Lindenmayer, D.B., Laurance, W.F. \& Franklin, J.F. (2012) Global Decline in Large Old Trees. Science 338: 1305-1306.

Martell, D.L., Gunn, E.A. \& Weintraub, A. (1998) Forest management challenges for operational researchers. European Journal of Operational Research 104: 1-17.

Page 24 of 40

https://mc06.manuscriptcentral.com/cjfr-pubs 
554 Martell, D.L. \& Sun, H. (2008) The impact of fire suppression, vegetation, and weather on the 555 area burned by lightning-caused forest fires in Ontario. Canadian Journal of Forest Research-Revue Canadienne De Recherche Forestiere 38: 1547-1563.

Mayor, S.J., Schaefer, J.A., Schneider, D.C. \& Mahoney, S.P. (2007) Spectrum of selection:

McGreer, M.T., Mallon, E.E., Vander Vennen, L.M., Wiebe, P.A., Baker, J.A., Brown, G.S., Tal

561

562

563

564

565

566

567

568

569

570

571

572

573

574

575

576 Avgar, T., Hagens, J., Kittle, A.M., Mosser, A., Street, G.M., Reid, D.E.B., Rodgers, A.R., Shuter, J., Thompson, I.D., Turetsky, M.J., Newmaster, S.G., Patterson, B. \& Fryxell, J.M. (2015) Selection for forage and avoidance of risk by woodland caribou (Rangifer tarandus caribou) at coarse and local scales. Ecosphere 6: 288

O'Brien, D., Manseau, M., Fall, A. \& Fortin, M.J. (2006) Testing the importance of spatial configuration of winter habitat for woodland caribou: An application of graph theory. Biological Conservation 130: 70-83.

Ohman, K. (2000) Creating continuous areas of old forest in long-term forest planning. Canadian Journal of Forest Research-Revue Canadienne De Recherche Forestiere 30: 1817-1823.

OMNR (2003) Ontario Base Maps. Ontario Ministry of Natural Resources. Peterborough, Ontario, CA. http://www.geographynetwork.ca/website/obm/viewer.htm. Accessed on: March 3, 2014.

OMNR (2006) Forest Management Units. Ontario ministry of Natural Resources. https://www.javacoeapp.lrc.gov.on.ca/geonetwork/srv/en/metadata.show?uuid=0104befe9493-4d9f-b45b-315063374032\&currTab=simple 
577 OMNR (2007) Strategic forest management model. Software version 3.2. Queen's printer for

578

579

580

581

582

583

584

585

586

587

588

589

590

591

592

593

594

595

596

597

598

599

Ontario, Toronto, ON, Canada.

OMNR (2009a) 2009-2019 Forest Management Plan for the Trout Lake Forest. (ed. N.R. Ontario Ministry of Natural Resources (Red Lake District, Domtar Pulp and Paper Products Inc.).

OMNR (2009b) Forest Resources Inventory Technical Specifications 2009. pp. 93. Queen's printer for Ontario, Toronto, ON, Canada. Available at http://www.ontario.ca/document/forest-resources-inventory-technical-specifications.

OMNR (2010) Caribou Range Boundary. Ontario Ministry of Natural Resources. Scholars Portal, Ontario Council of University Libraries. http://geo2.scholarsportal.info/.

OMNR (2014) Forest Management Guide for Boreal Landscapes. Toronto: Queen's Printer for Ontario. 104 pp.

Parker, K.L., Barboza, P.S. \& Stephenson, T.R. (2005) Protein conservation in female caribou (Rangifer tarandus): Effects of decreasing diet quality during winter. Journal of Mammalogy 86: 610-622.

Penner, M., Woods, M., Parton, J. \& Stinson, A. (2008) Validation of empirical yield curves for natural-origin stands in boreal Ontario. Forestry Chronicle 84: 704-717.

Pulkki, R. 2003. Minimizing negative environmental impacts of forest harvesting operations. In Towards sustainable management of the boreal forest. Edited by P.J. Burton and M. C. and D.W. Smith and W.L. Adamowicz. NRC Research Press, Canada. pp. 581-628.

R Development Core Team (2015) R: A language and environment for statistical computing v. 3.1.2. R Foundation for Statistical Computing. Retrived from http://www.R-project.org/, Vienna, Austria

Page 26 of 40

https://mc06.manuscriptcentral.com/cjfr-pubs 
600 601 602 603 604 605 606 607 608 609 610 611 612 613 614 615 616 617 618 619 620 621 622

Racey, G., Harris, A., Gerrish, L., Armstrong, E., McNicol, J. \& Baker, J. (1999) Forest management guidelines for the conservation of woodland caribou: a landscape approach. Ontario Ministry of Natural Resources, Thunder Bay, Ontario. 69 pp.

Rayfield, B., James, P.M.A., Fall, A. \& Fortin, M.-J. (2008) Comparing static versus dynamic protected areas in the Quebec boreal forest. Biological Conservation 141: 438-449.

Saura, S., Estreguil, C., Mouton, C. \& Rodriguez-Freire, M. (2011) Network analysis to assess landscape connectivity trends: Application to European forests (1990-2000). Ecological Indicators 11: 407-416.

Savage, D.W., Martell, D.L. \& Wotton, B.M. (2010) Evaluation of two risk mitigation strategies for dealing with fire-related uncertainty in timber supply modelling. Canadian Journal of Forest Research-Revue Canadienne De Recherche Forestiere 40: 1136-1154.

Schaefer, J.A. (2003) Long-term range recession and the persistence of caribou in the taiga. Conservation Biology 17: 1435-1439.

Thompson, I., Wiebe, P.A., Mallon, E., Rodgers, A.R., Fryxell, J.M., Baker, J.A. \& Reid, D. (2015) Factors influencing the seasonal diet selection by woodland caribou in boreal forests in Ontario. Canadian Journal of Zoology 93(2): 87-98.

Tittler, R., Messier, C. \& Fall, A. (2012) Concentrating anthropogenic disturbance to balance ecological and economic values: applications to forest management. Ecological Applications 22: 1268-1277.

Urban, D. \& Keitt, T. (2001) Landscape connectivity: A graph-theoretic perspective. Ecology 82: 1205-1218.

Venier, L.A., Thompson, I.D., Fleming, R., Malcolm, J., Aubin, I., Trofymow, J.A., et al. (2014) Effects of natural resource development on the terrestrial biodiversity of Canadian boreal 

forests. Environmental Reviews 22: 457-490.

624 Vors, L.S., Schaefer, J.A., Pond, B.A., Rodgers, A.R. \& Patterson, B.R. (2007) Woodland 625 caribou extirpation and anthropogenic landscape disturbance in Ontario. Journal of $626 \quad$ Wildlife Management 71: 1249-1256.

627 Williams, J.C., ReVelle, C.S. \& Levin, S.A. (2004) Using mathematical optimization models to 628 design nature reserves. Frontiers in Ecology and the Environment 2: 98-105.

629 Wittmer, H.U., Sinclair, A.R.E. \& McLellan, B.N. (2005) The role of predation in the decline 630 and extirpation of woodland caribou. Oecologia 144: 257-267. 
631 Tables

632 Table 1. Description of woodland caribou habitat classifications using Forest Resource Inventory (FRI) data. Listed is the rank of 633 preference, landscape type, FRI forest units, age, description and the associated cost used within the cost surface. These ranks and 634 values were derived from O'Brien et al. (2006) and the Environment Canada (2011) critical habitat assessment.

\begin{tabular}{|c|c|c|c|c|c|}
\hline Rank & Landscape Type & FRI Forest Units & $\begin{array}{c}\text { Age } \\
\text { (Years) }\end{array}$ & Description & Cost \\
\hline 1 & $\begin{array}{l}\text { Mature Jack Pine, Shallow } \\
\text { Soils, and Rocky Outcrops }\end{array}$ & PJP, SHA, and RCK & $\geq 60$ & $\begin{array}{l}\text { Mature upland Jack Pine, } \\
\text { shallow soil, and rocky areas }\end{array}$ & 1 \\
\hline 2 & Treed Muskeg & TMS & - & Treed muskeg & 1.1 \\
\hline 3 & Mature Conifer Mixedwood & $\begin{array}{l}\text { PJM, CMX, PRW, SBM, } \\
\text { and SBP }\end{array}$ & $>71$ & $\begin{array}{l}\text { Mature upland conifer } \\
\text { mixedwood and Black Spruce }\end{array}$ & 1.75 \\
\hline 4 & Mature Lowland Conifer & OCL and SBL & $\geq 60$ & $\begin{array}{l}\text { Mature lowland conifer } \\
\text { mixedwood and Black Spruce }\end{array}$ & 1.75 \\
\hline 5 & $\begin{array}{l}\text { Intermediate Upland } \\
\text { Mixedwood }\end{array}$ & $\begin{array}{l}\text { CMX, HMX, PJM, and } \\
\text { SBM }\end{array}$ & $\geq 46$ & $\begin{array}{l}\text { Mixedwood stands of } \\
\text { intermediate age }\end{array}$ & 2 \\
\hline 6 & $\begin{array}{l}\text { Young Conifers and } \\
\text { Hardwoods }\end{array}$ & $\begin{array}{l}\text { POA and BWD (along with } \\
\text { all other conifer stands) }\end{array}$ & - & $\begin{array}{l}\text { All dominant hardwood stands } \\
\text { and younger conifer stands }\end{array}$ & 2 \\
\hline 7 & Water and Wetlands & WAT and OMS & - & $\begin{array}{l}\text { Lakes, Rivers, and marsh } \\
\text { areas }\end{array}$ & 3.5 \\
\hline 8 & Recent Disturbance & $\begin{array}{l}\text { All merchantable wood } \\
\text { units }\end{array}$ & $<20$ & $\begin{array}{l}\text { Recently disturbed areas } \\
\text { (e.g., harvest, fire) }\end{array}$ & 5 \\
\hline 9 & Linear Features & - & - & $\begin{array}{l}\text { Current road and utility line } \\
\text { infrastructure }\end{array}$ & 10 \\
\hline
\end{tabular}


635 Table 2. Summary statistics for the final landscape at the end of the 100 year planning horizon

636 using a median dispersal distance of $40 \mathrm{~km}$. Shown is the number of woodland caribou habitat

637 patches, number of links, total preferred habitat area, and the overall landscape Equivalent

638 Connected Area (ECA; a measure of woodland caribou habitat connectivity and area).

\begin{tabular}{lcccc} 
Strategy & $\begin{array}{c}\text { Number of } \\
\text { Patches }\end{array}$ & $\begin{array}{c}\text { Number } \\
\text { of Links }\end{array}$ & $\begin{array}{c}\text { Habitat } \\
\text { Amount (ha) }\end{array}$ & $\begin{array}{c}\text { ECA } \\
\text { (ha) }\end{array}$ \\
\hline No Harvest & 1,543 & 3,955 & $121,643.8$ & $90,228.5$ \\
Heuristic & 1,027 & 2,650 & $95,856.3$ & $75,370.6$ \\
Mosaic & 1,194 & 3,123 & $68,612.5$ & $45,257.2$ \\
Relaxed & 832 & 2,198 & $44,593.8$ & $28,929.5$ \\
\hline
\end{tabular}

639

640 


\section{Figure Legends}

642 Figure 1. The study area, Trout Lake Forest Management Unit (FMU), with respect to woodland 643 caribou distribution (light grey) and all FMUs (dark grey outline) in the province of Ontario.

644 Woodland caribou range data is from OMNR (2010) and FMU data from OMNR (2006).

645 Figure 2. A schematic diagram of the harvesting heuristic.

646 Figure 3. (A) The initial habitat classification for woodland caribou (1 - preferred; 9 - least 647 preferred) and the resulting (B) harvest value for each forest stand using the harvesting heuristic 648 on the Trout Lake forest management unit (light grey - less desirable; black - more desirable). 649 Figure 4. The predicted (A) mean equivalent connected area (a measure of woodland caribou 650 habitat area and its connectivity) calculated using five movement distances (median movement 651 of $1,10,25,40,80 \mathrm{~km}$ ) under four management strategies for no harvesting (solid black), 652 heuristic (dashed black), caribou mosaic (solid grey), and relaxed caribou mosaic (dashed grey) 653 strategies with standard deviation in light grey. Solutions for each movement distance are also 654 shown for (B) no harvesting, (C) harvesting heuristic, (D) caribou mosaic and (E) relaxed 655 caribou mosaic strategies.

656 Figure 5. The area of habitat in (A) non-harvested and (B) harvested areas over the course of a 657 100-year planning horizon for each harvesting strategy. Also shown is the number of preferred 658 habitat patches within (C) non-harvested and (D) harvested areas.

659 Figure 6. Maps showing preferred woodland caribou habitat (black), least-cost links (dark grey), 660 and reserves (light grey) for the terminal landscape (after 100 years of harvest scheduling) for the 661 four harvesting strategies. Harvesting strategies include: (A) no harvesting, (B) harvesting 662 heuristic, (C) caribou mosaic, and (D) relaxed caribou mosaic. 
663 Figure 7. Stands that are selected for harvest once (light grey), twice (dark grey) and in a few 664 cases, three (black) times over the planning horizon (100 years) using the (A) harvesting 665 heuristic, (B) caribou mosaic, and (C) relaxed caribou mosaic strategies.

666 Figure 8. The percent of the Trout Lake Forest Management Unit disturbed for woodland 667 caribou over the course of the planning horizon using the four different harvesting strategies.

668 Here linear features (roads and utility corridors) alongside recently disturbed areas ( $<20$ year old 669 forest) with a $500 \mathrm{~m}$ buffer of influence are summed to give the percent area disturbed. 
$670 \quad$ Figure 1.

671

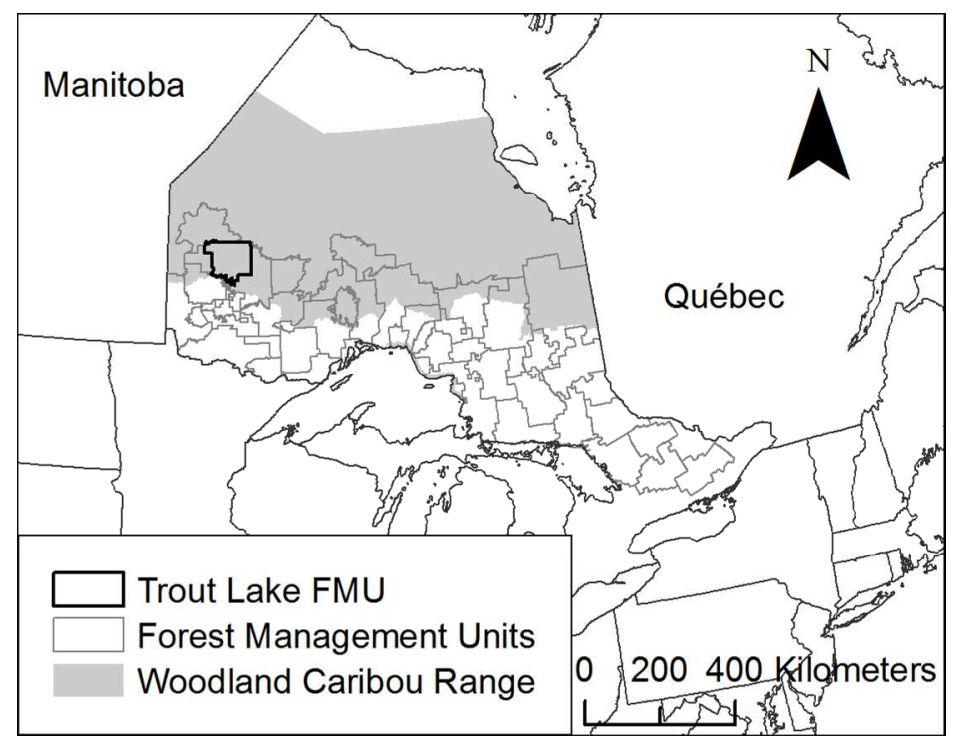

672 
673 Figure 2.

674

675

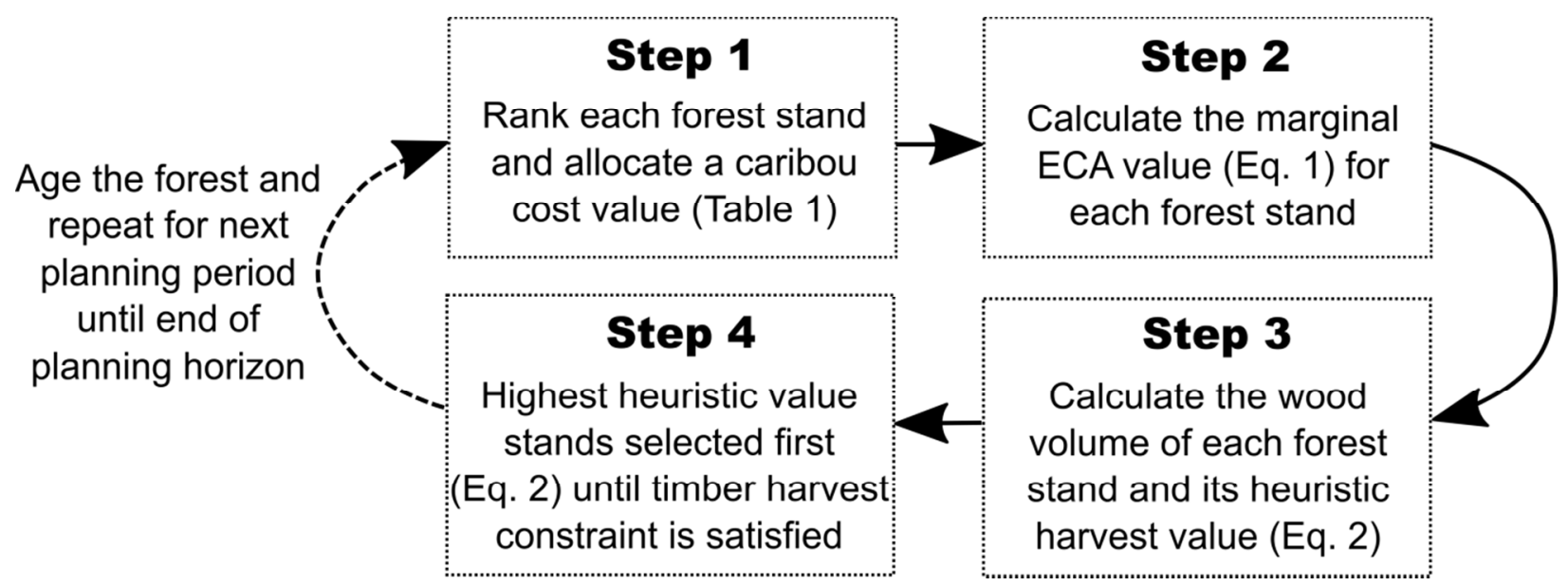

676

677 
$678 \quad$ Figure 3.
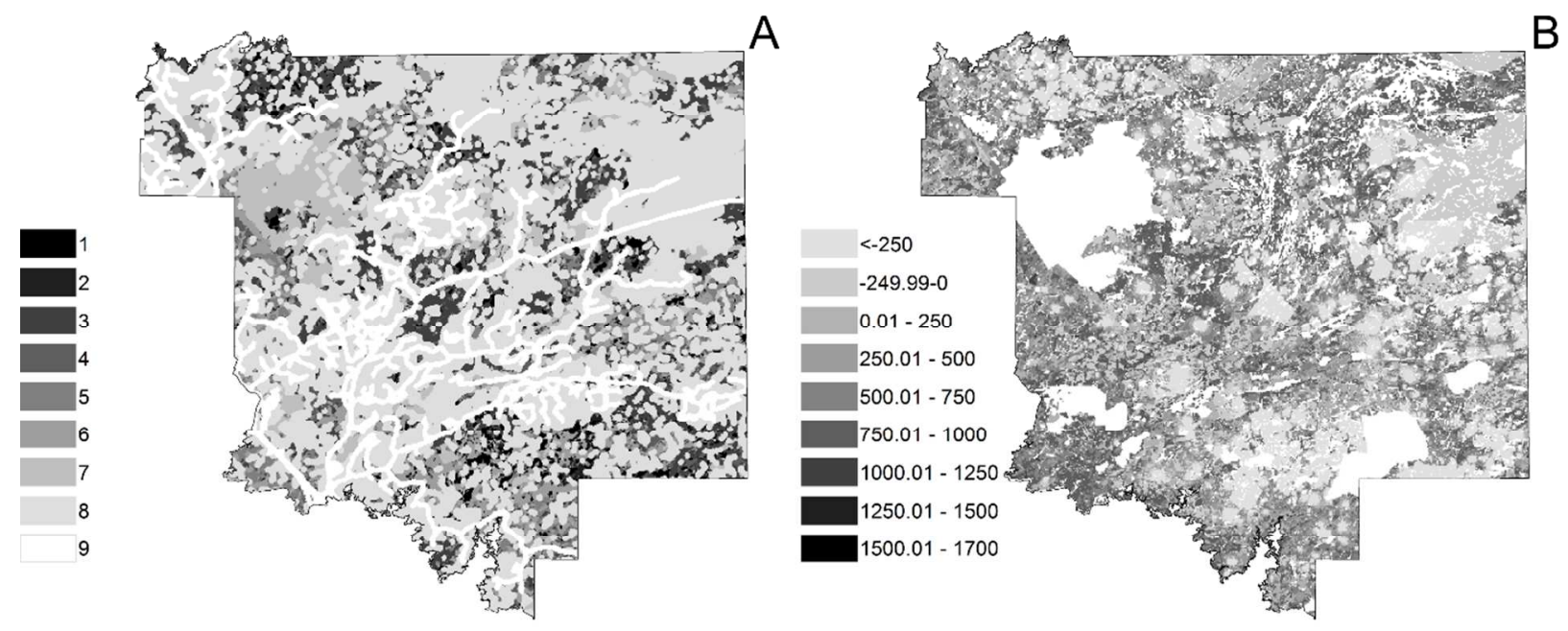

679

680

Page 35 of 40

https://mc06.manuscriptcentral.com/cjfr-pubs 
$681 \quad$ Figure 4.
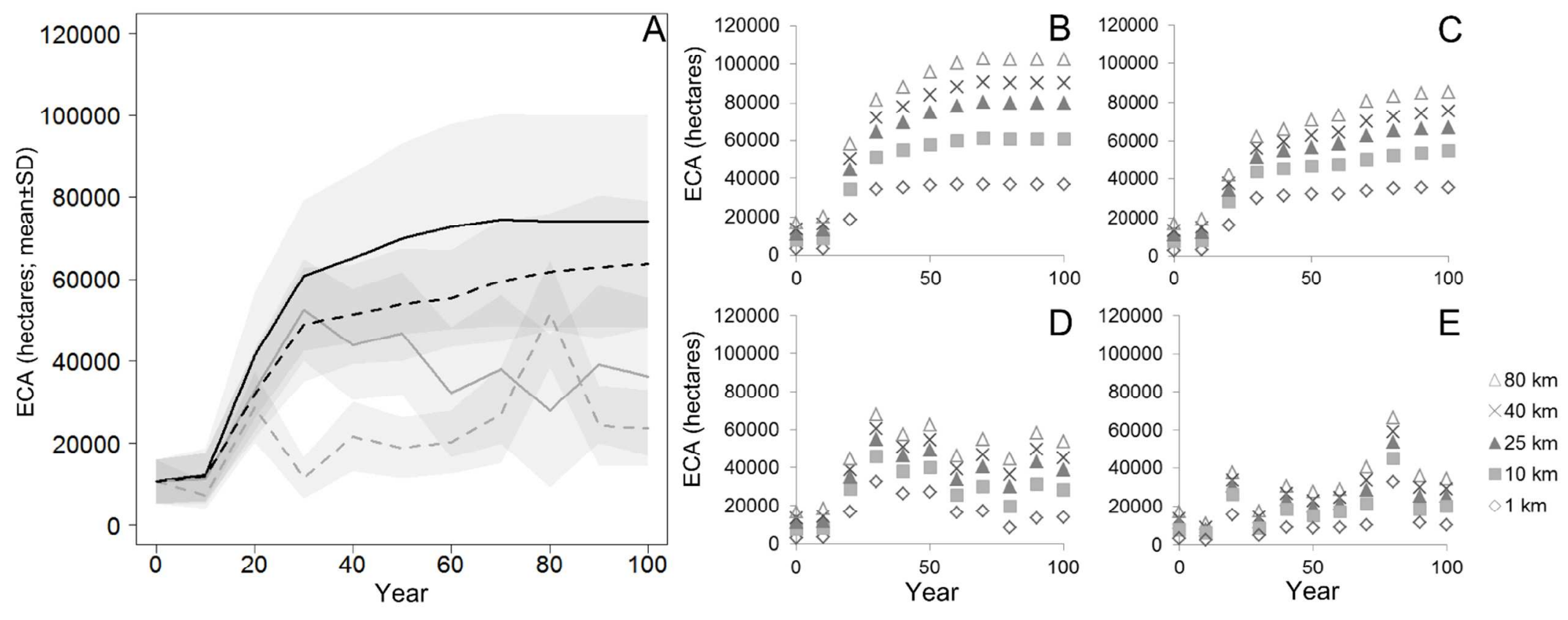

683

Page 36 of 40 
$684 \quad$ Figure 5.

685
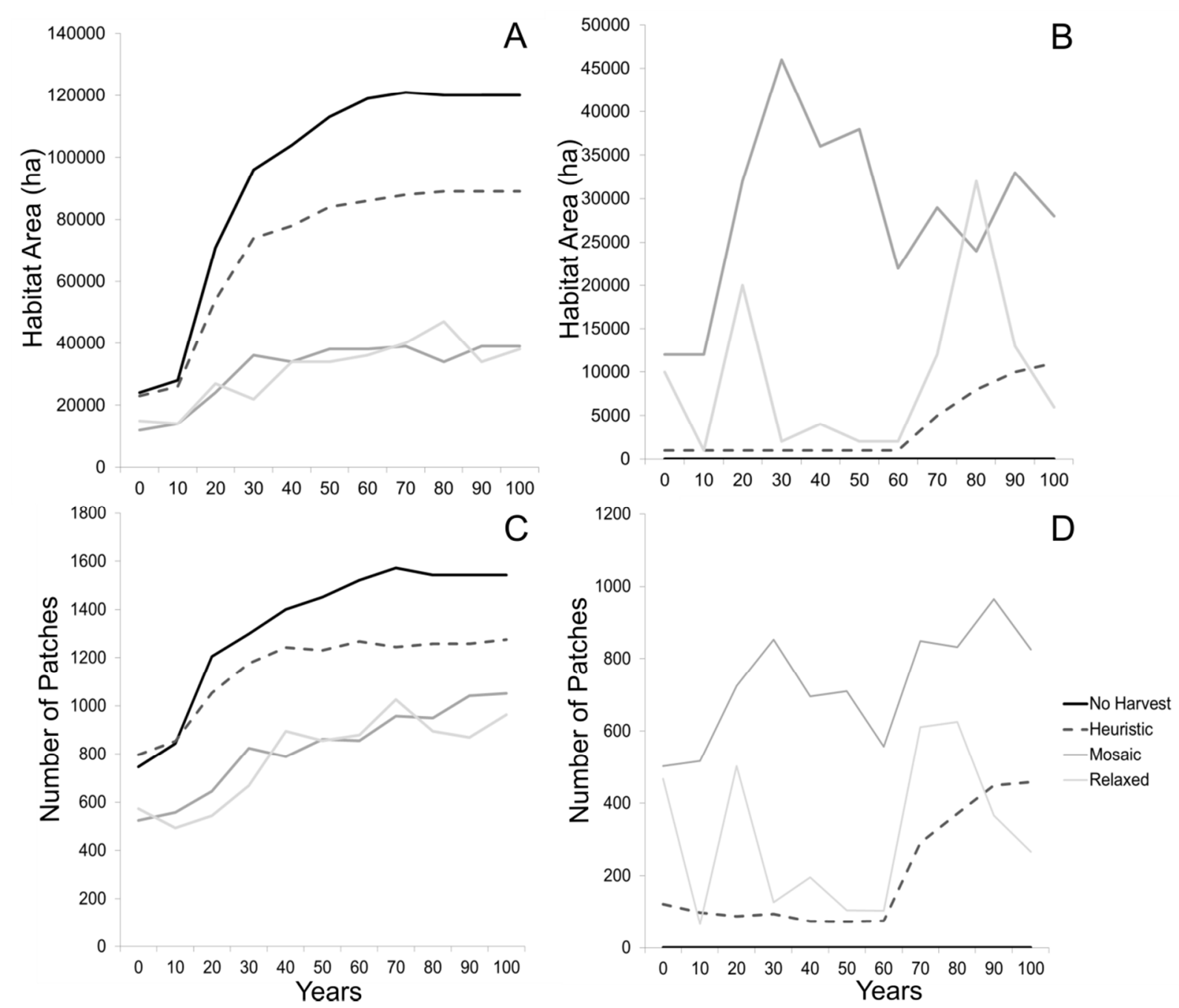

686

687

688

689

690

691

Page 37 of 40

https://mc06.manuscriptcentral.com/cjfr-pubs 

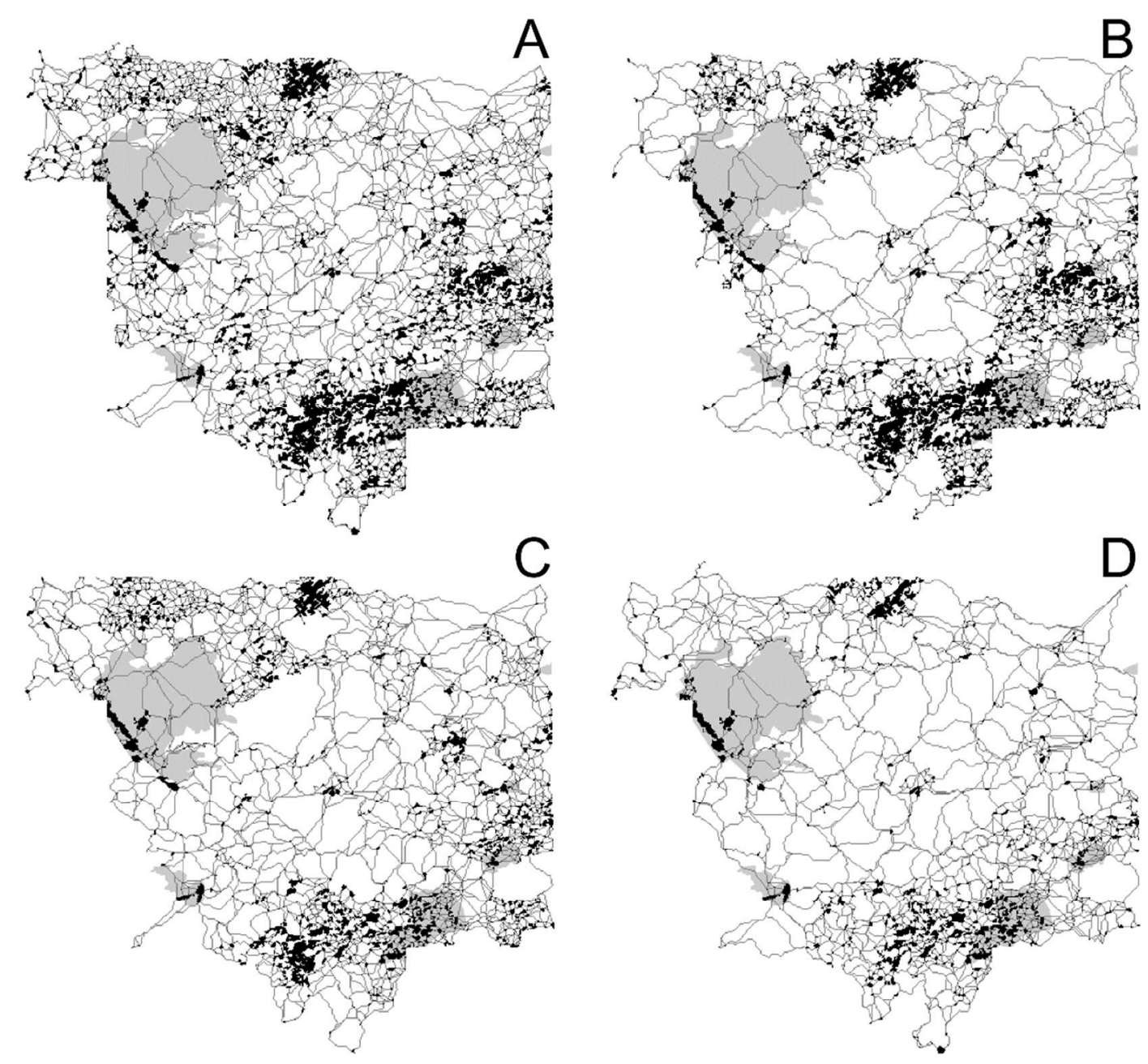

693

694

Page 38 of 40

https://mc06.manuscriptcentral.com/cjfr-pubs 
$695 \quad$ Figure 7.

696
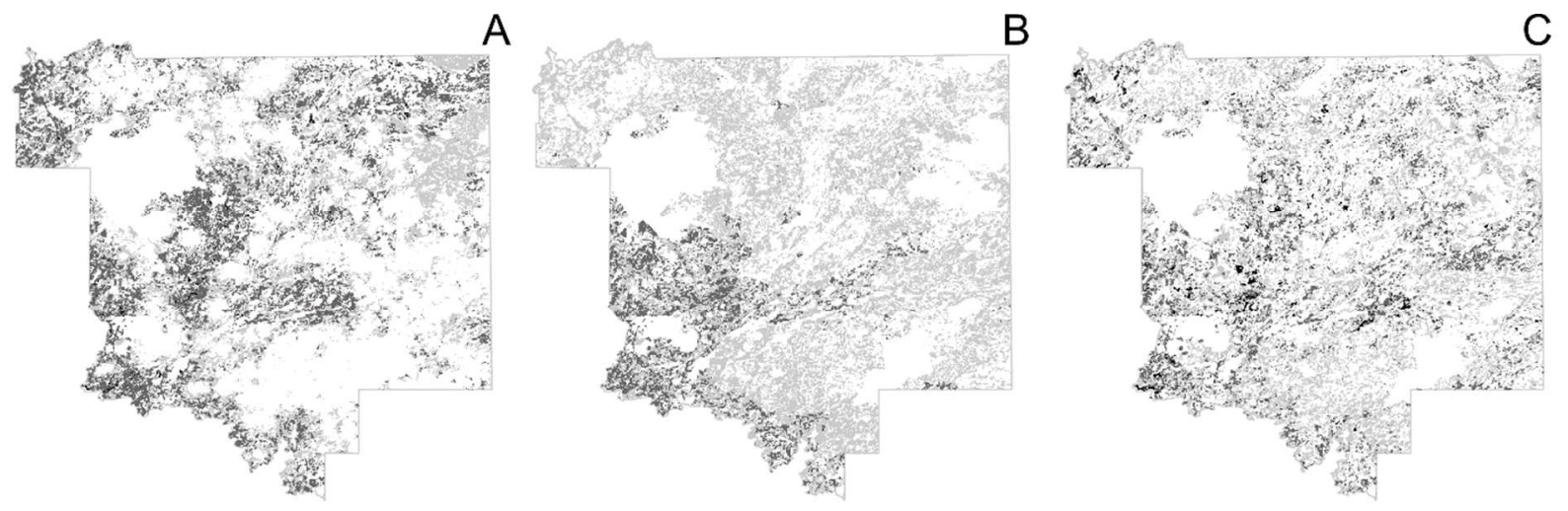

697

Page 39 of 40

https://mc06.manuscriptcentral.com/cjfr-pubs 
$698 \quad$ Figure 8.

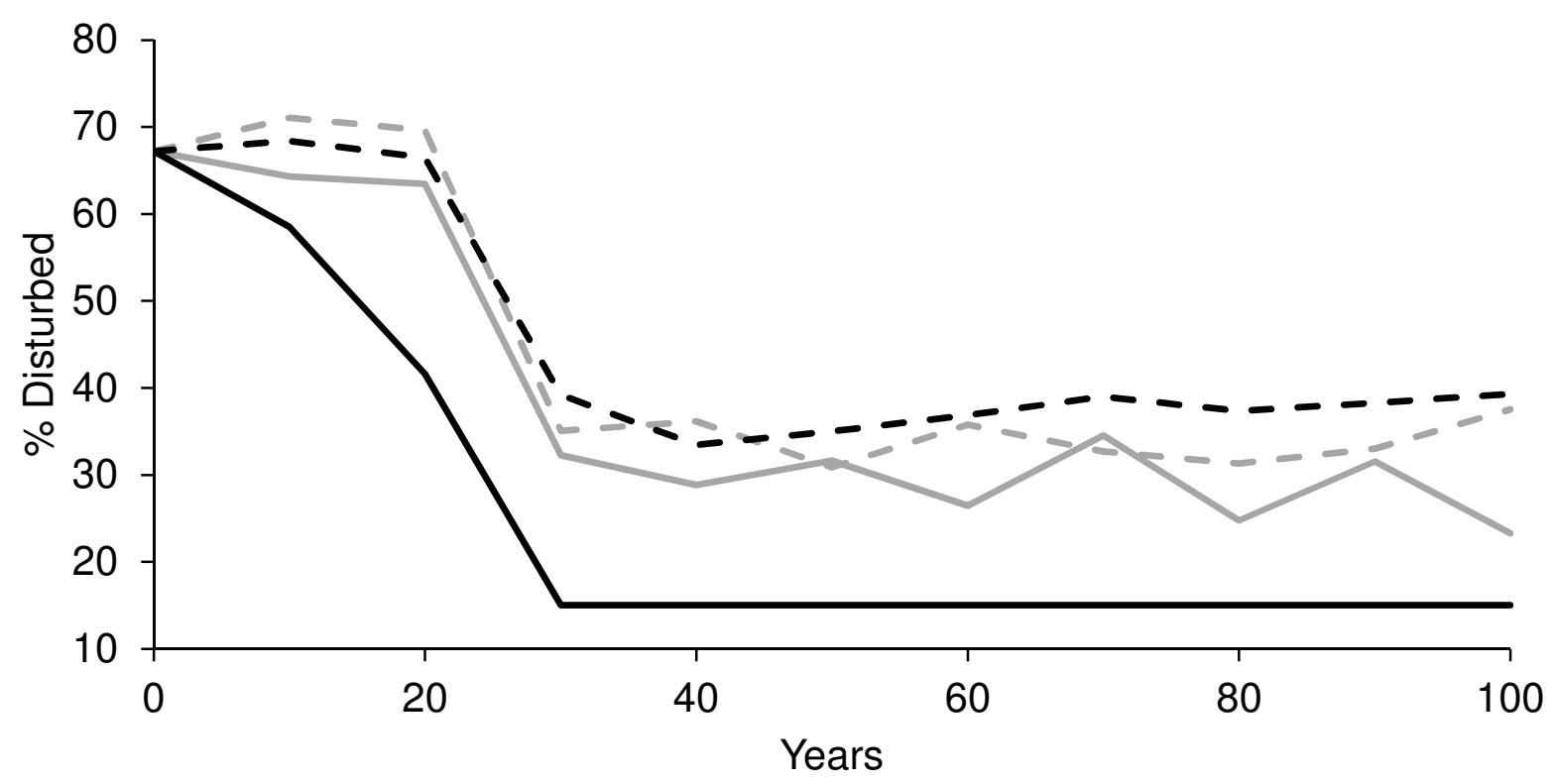

699

- Relaxed

Caribou Mosaic - - Heuristic

No Harvesting

700

701

702

703

704

705

706

Page 40 of 40

https://mc06.manuscriptcentral.com/cjfr-pubs 


\section{Supplementary Text}

\section{Parameterizing maximum product probability}

Maximum product probability $\left(p_{i j}\right)$ is defined as the maximum probability of movement across all potential paths between patches $i$ and $j$, including paths that utilize other patches (Saura et al. 2011). For example, if patches are closer together they will have a maximum product probability of movement that will be a function of direct dispersal between the patches, but if they are further apart it would likely consist of steps through intermediary habitat patches (or stepping stones; see Saura et al. 2011 for details; Figure S3). Using the derived spatial graph based on least-cost paths, we calculated the probability of direct dispersal based on an alpha of 0.5 and a potential median movement distance of $40 \mathrm{~km}$ for woodland caribou. While the specific movement distances may differ for woodland caribou depending on the population, season, or region, woodland caribou are highly mobile and travel long distances between areas used for early winter, late winter, spring, calving, and summer. The distances covered between these seasons can vary between approximately $10-25 \mathrm{~km}$ in distance apart, for a total annual median distance of movement that is approximately $80 \mathrm{~km}$ for populations in northwestern Ontario (Ferguson and Elkie 2004b, a). Further, over the course of a year, the daily median movement rate for woodland caribou can be approximately $1 \mathrm{~km}$ per day (Rettie \& Messier 2001, Ferguson \& Elkie 2004b). We performed a sensitivity analysis of how each of five median movement distances $(1,10,25,40$ and $80 \mathrm{~km})$ may influence the outcomes of harvesting decisions by our heuristic (see Figure 4 and S4). We find that the overall landscape connectivity (ECA) may differ with median dispersal distance (Figure S4) and that this can translate to differences in the overall amount of habitat found on the landscape (Figure 4). In particular, the amount of habitat available to woodland caribou over the planning horizon is the largest for both $40 \mathrm{~km}$ and $80 \mathrm{~km}$

\section{Page 1 of 7}


median dispersal distances. Thus, as we are trying to improve and maintain the amount of woodland caribou habitat, we use a median dispersal distance of $40 \mathrm{~km}$ for all our subsequent analysis, because $80 \mathrm{~km}$ does not provide a measurable improvement over the 100 -year planning horizon and $40 \mathrm{~km}$ represents a balance between daily, seasonal and annual movement of woodland caribou (Figure 4 and S4; Ferguson and Elkie 2004b, a).

\section{Supplementary Figures}
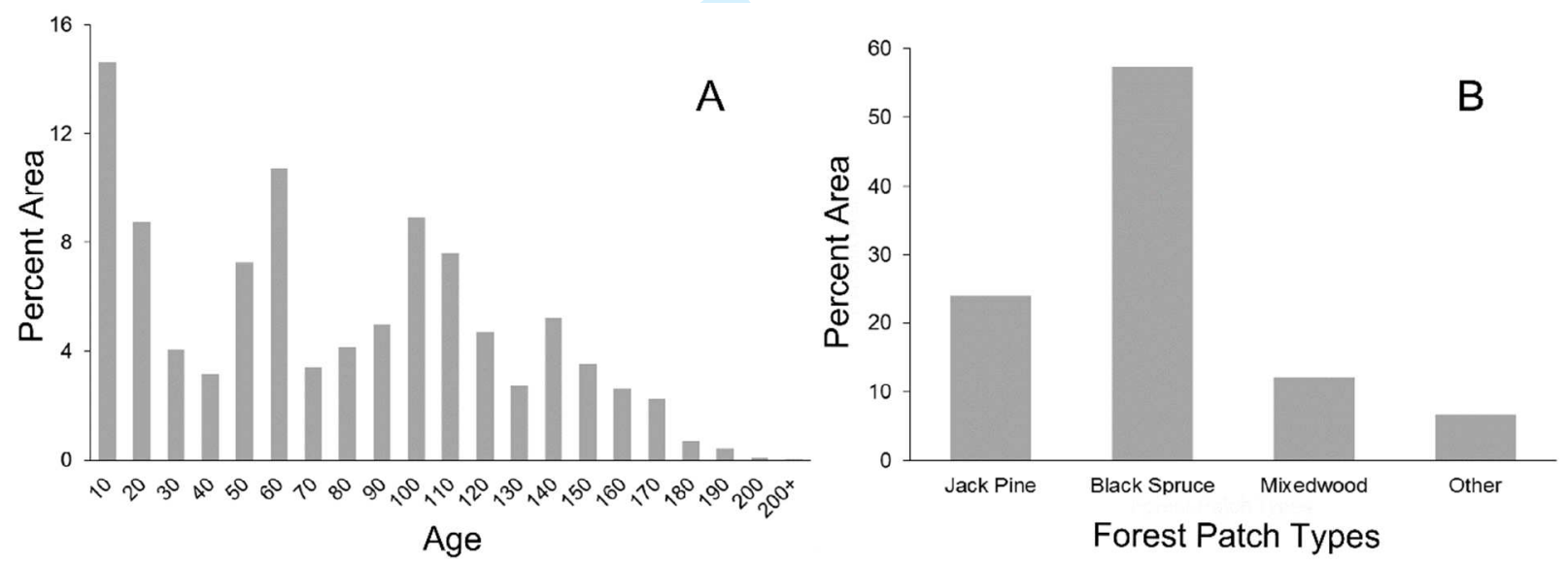

Figure S1. (A) Age class distribution and (B) species composition of forest stands within the Trout Lake Forest Management Unit for the year 2012. 

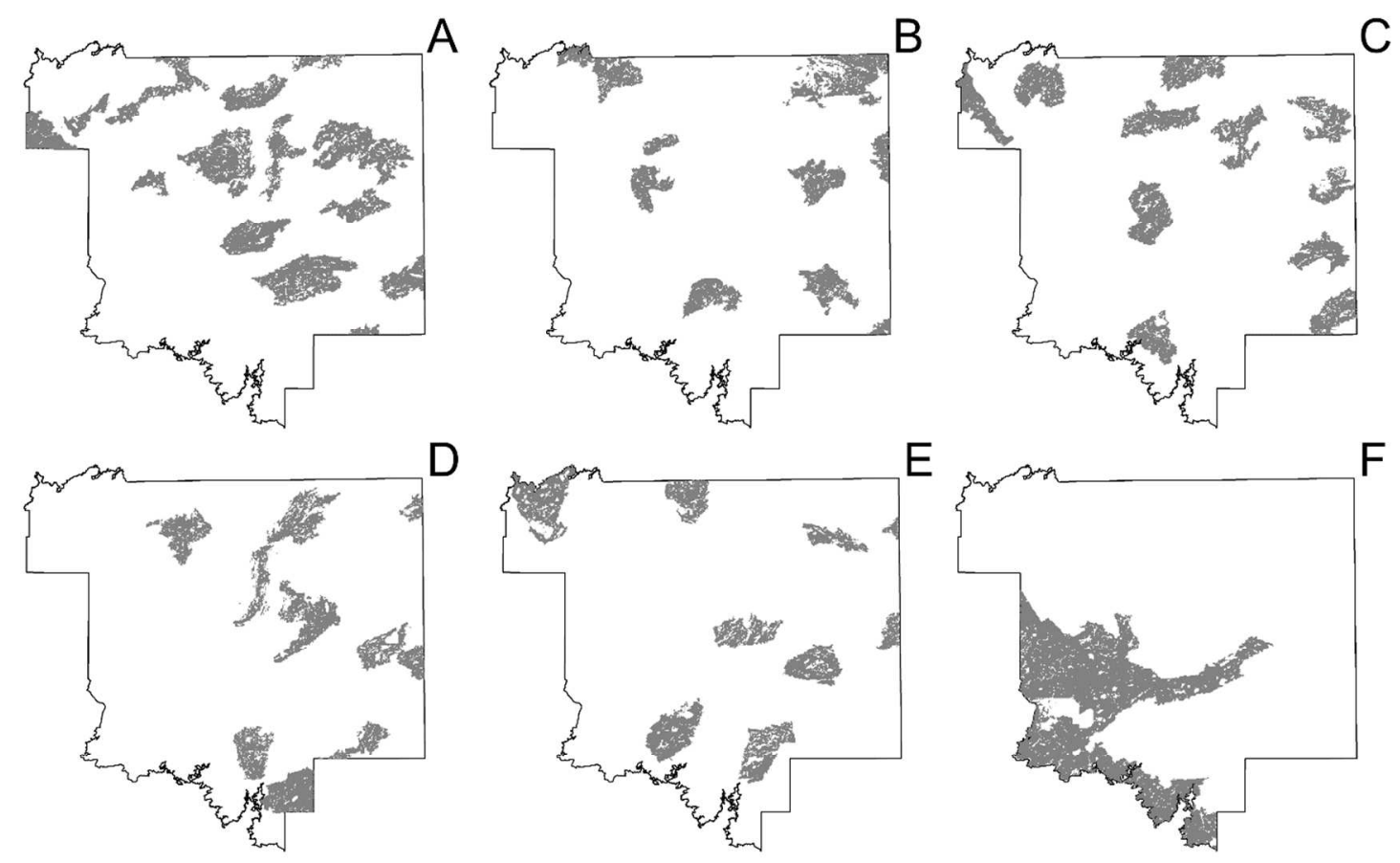

Figure S2. Spatial distribution of harvest under the caribou mosaic harvest scheduling strategy for the Trout Lake Forest Management Unit. Harvest blocks (grey) are stratified temporally for years (A) 1-10 (and 91-100), (B) 11-30, (C) 31-50, (D) 51-70, (E) 71-90 and (F) anytime. 


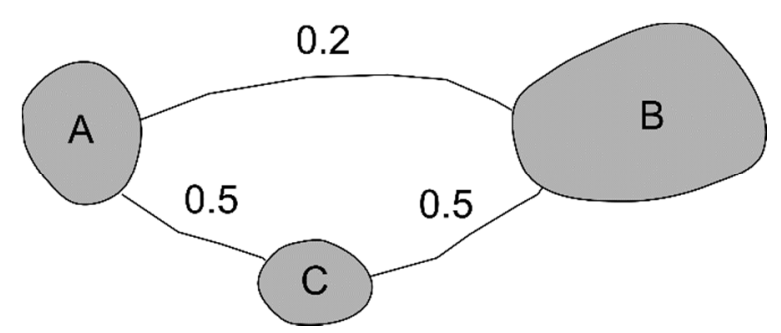

Figure S3. A simple three patch system with three links of direct dispersal. In this case, the probability of direct dispersal between patch $\mathrm{A}$ and $\mathrm{B}$ is 0.2 , but the maximum product probability of dispersal between $\mathrm{A}$ and $\mathrm{B}$, using patch $\mathrm{C}$ as a stepping stone, is $0.5 \times 0.5=0.25$ as this value is greater than the direct dispersal. Adapted from Saura and Pascual-Hortal (2007). 


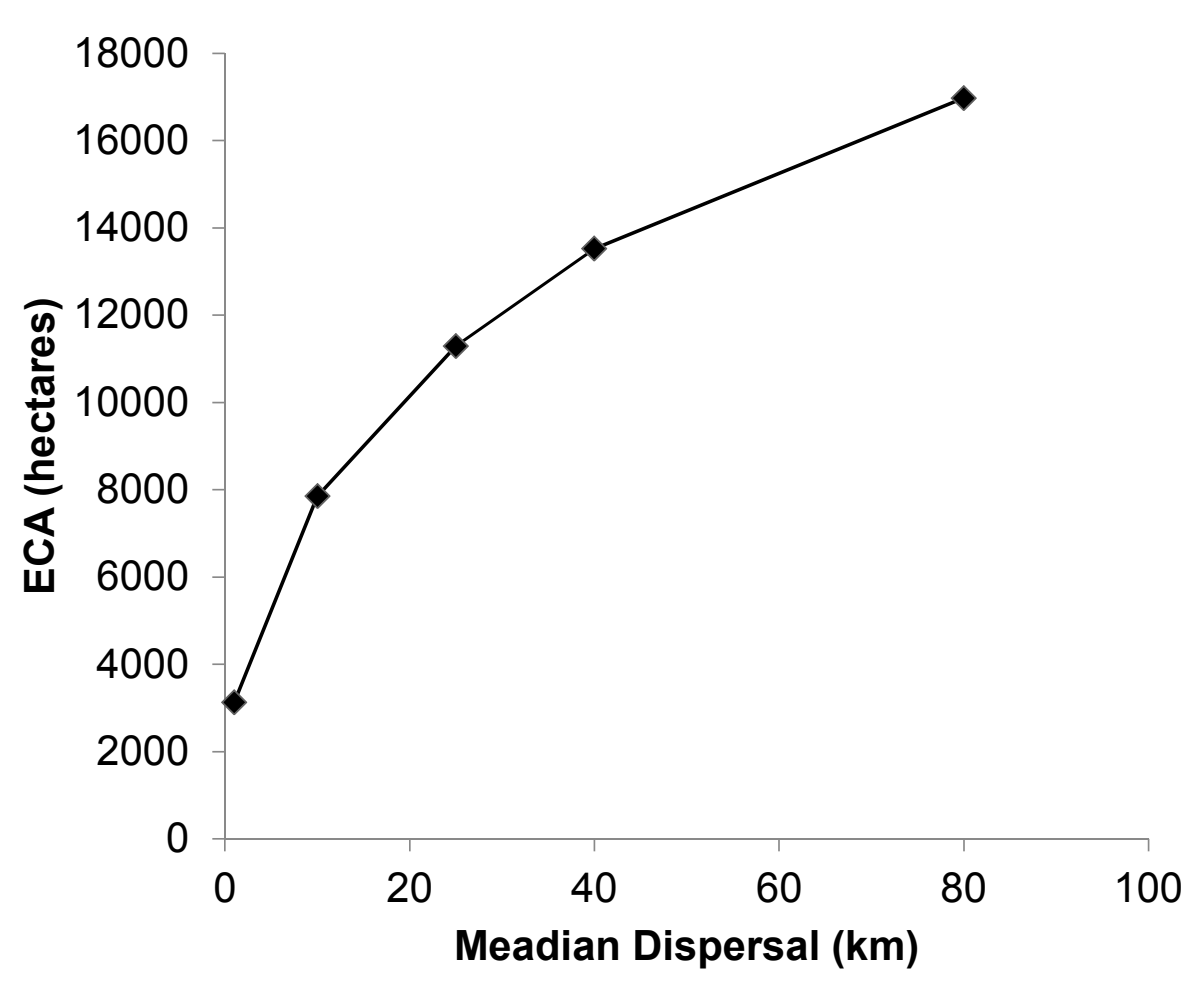

Figure S4. Sensitivity analysis of the Equivalent Connected Area (ECA) metric under five different median dispersal distances (using $\alpha=0.5$ ). Shown is the ECA of the initial landscape using different median dispersal distances $(1,10,25,40,80 \mathrm{~km})$. 


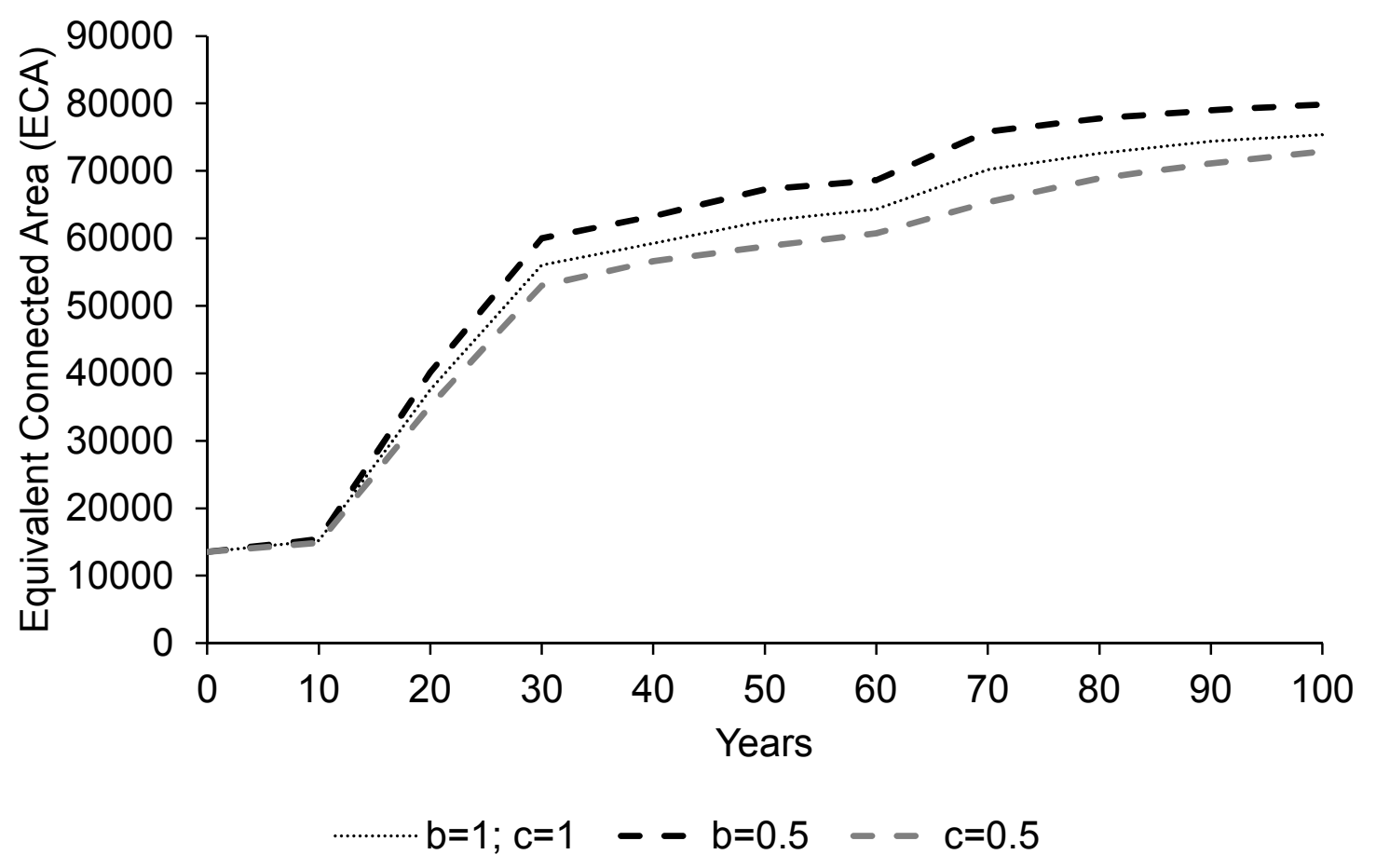

Figure S5. The equivalent connected area (a measure of habitat connectivity and area) using the harvesting heuristic strategy under different values for both parameters $b$ and $c(0.5$ and 1$)$ in the Trout Lake Forest Management Unit. Here we hold one value constant at 1 while changing the other. Values are calculated using a median dispersal distance of $40 \mathrm{~km}$ and alpha value of 0.5 . 


\section{References}

Ferguson, S. H., and P. C. Elkie. 2004a. Habitat requirements of boreal forest caribou during the travel seasons. Basic and Applied Ecology 5:465-474.

Ferguson, S. H., and P. C. Elkie. 2004b. Seasonal movement patterns of woodland caribou (Rangifer tarandus caribou). Journal of Zoology 262:125-134.

Rettie, W. J., and F. Messier. 2001. Range use and movement rates of woodland caribou in Saskatchewan. Canadian Journal of Zoology-Revue Canadienne De Zoologie 79:19331940.

Saura, S., C. Estreguil, C. Mouton, and M. Rodriguez-Freire. 2011. Network analysis to assess landscape connectivity trends: Application to European forests (1990-2000). Ecological Indicators 11:407-416.

Saura, S. and Pascual-Hortal, L. 2007. CONEFOR SENSINODE 2.2: User's Manual. University of Lleida, Spain. http:/www.conefor.org/files/usuarios/CS22manual.pdf. 